\title{
LVIII. On certain improvements in the construction and supply of the hydro-oxygen blowpipe, by which platinum may be fused in the large way
}

\section{Robert Hare M.D.}

To cite this article: Robert Hare M.D. (1847) LVIII. On certain improvements in the construction and supply of the hydro-oxygen blowpipe, by which platinum may be fused in the large way, Philosophical Magazine Series 3, 31:209, 356-366, DOI: 10.1080/14786444708645868

To link to this article: http://dx.doi.org/10.1080/14786444708645868

冓 Published online: 30 Apr 2009.

Submit your article to this journal $[\pi$

山 Article views: 3

View related articles 
The plate in the centre of the stream shows less rusting than the one at the edge in still water; but judging from the analogous case of the copper sheathing of a ship, it should waste away the fastest, the particles of peroxide of iron as they are formed being removed by the force of the stream, while the voltaic current developed during this action only circulates to some other point of the same plate, or belongs to what is called local action.

From the above results, the benefit to be obtained in a constant battery by making the negative plate rotate, should be apparent; but to prevent waste it would still be necessary to employ one of the more costly metals, which are not liable to oxidation.

In concluding these experiments, I may again notice, that a tube of oxygen suspended over a plate of iron in still water has the same effect as the current of the stream, converting the oxygenated plate into a platinode. The carbonic acid present in all surface water may by some be thought to perform an essential part in the ordinary rusting of iron. But where every care is taken to exclude this gas from a tube filled with oxygen, a small quantity of water, and a piece of iron, the oxidation of the iron proceeds with rapidity, accompanied by changes which appear to me to preclude the idea that even a trace of carbonic acid can be essential. The oxygen gas disappears; at first an abundant formation of red or peroxide of iron is seen; then, after the supply of oxygen has decreased, the green-coloured protoxide is gradually formed. These two oxides afterwards begin slowly to unite, and form the well-known black or magnetic oxide. In an experiment of this kind every trace of the red and green-coloured oxides had disappeared at the end of three months from the time of closing the tube, and there remained only an inky precipitate, which was proved to be the black oxide of iron.

LVIII. On certain Improvements in the Construction and Supply of the Fydro-Oxygen Blowpipe, by rohich Platinum may befused in the large way. By Robert HaRe, M.D.*

$\mathrm{N}^{\mathrm{N}}$ my return from Europe in 1836, I was very much in want of a piece of platinum of a certain weight, while many more scraps than were adequate to form such a piece were in my possession. This induced new efforts to extend the power of my blowpipe; and after many experiments, I succeeded so as to fuse twenty-eight ounces of platinum into one mass.

- Communicated by the Author. 
Although small lumps of platinum had been fused by many operators with the hydro-oxygen blowpipe as well as myself, it had not, up to the year 1837, been found sufficiently competent to enable artists to resort to this process. I am informed by Mr. Saxton, that some efforts which were made while he was in London were so little successful, that the project was abandoned. There was an impression that the metal was rendered less malleable when fused upon charcoal, as in the experiments alluded to. This is contradicted by my experiments, agreeably to which fused platinum is as malleable as the best specimens obtained by the Wollaston process, and is less liable to flake. Dr. Ure, on seeing specimens of platinum which I had elaborated and fused in the form of wire, of leaf, ingots and plate, said that there was no one in Europe who could fuse platinum in such masses. He also informed me that it had been found so difficult to weld platinum, that no resort was had to that process. In this I concur, having had the welding tried by a skilful smith, both with a forge heat, and with a heat given by the hydro-oxygen blowpipe. An incorporation of two ingots was effected on their being hammered together, when heated nearly to fusion; but on hammering the resulting mass cold, a separation took place along the joint by which the ingots were united.

The difficulty seems to arise from the rapidity with which the platinum becomes refrigerated. It seems to have a less capacity for heat than iron; and, not burning in the air as iron does, has not the benefit of the heat acquired by iron from its own combustion with atmospheric oxygen.

Lately, by means of the instrument and process which it is my object here to describe, I have been enabled to obtain malleable platinum directly from the ore, by the continued application of the flame. From some specimens of platinum I have procured as much as ninety per cent. of malleable metal. The malleability is not inferior to that of the best specimens obtained by reducing it to the state of sponge, through the agency of aqua regia and sal-ammoniac. There is however a greater liability to tarnish, arising probably from the presence of a minute portion of palladium.

Of the fusion of iridium and rhodium, I have already given an account in the Bulletin of the American Philosophical Society, which was subsequently embodied in an article in this Journal for August 1847.

It remains now to give an account of the apparatus employed in the fusion of platina on a large scale.

Fig. 1 represents the association of fifteen jet-pipes of platinum with one large pipe B D at their upper ends, so that 
their bores communicate, by means of an appropriate brass casting, with that of the large pipe, the joints secured by hard solder. Their lower extremities are made to protrude about half an inch from a box A, of cast brass, their junctures, with the appropriate perforations severally made for them, being secured by silver solder. They come out obliquely in a line along one corner of the box, an interval of about a quarter of an inch alternating with each orifice. By means of flanges, the brass box is secured to a conical frustum of copper (fig. 2),

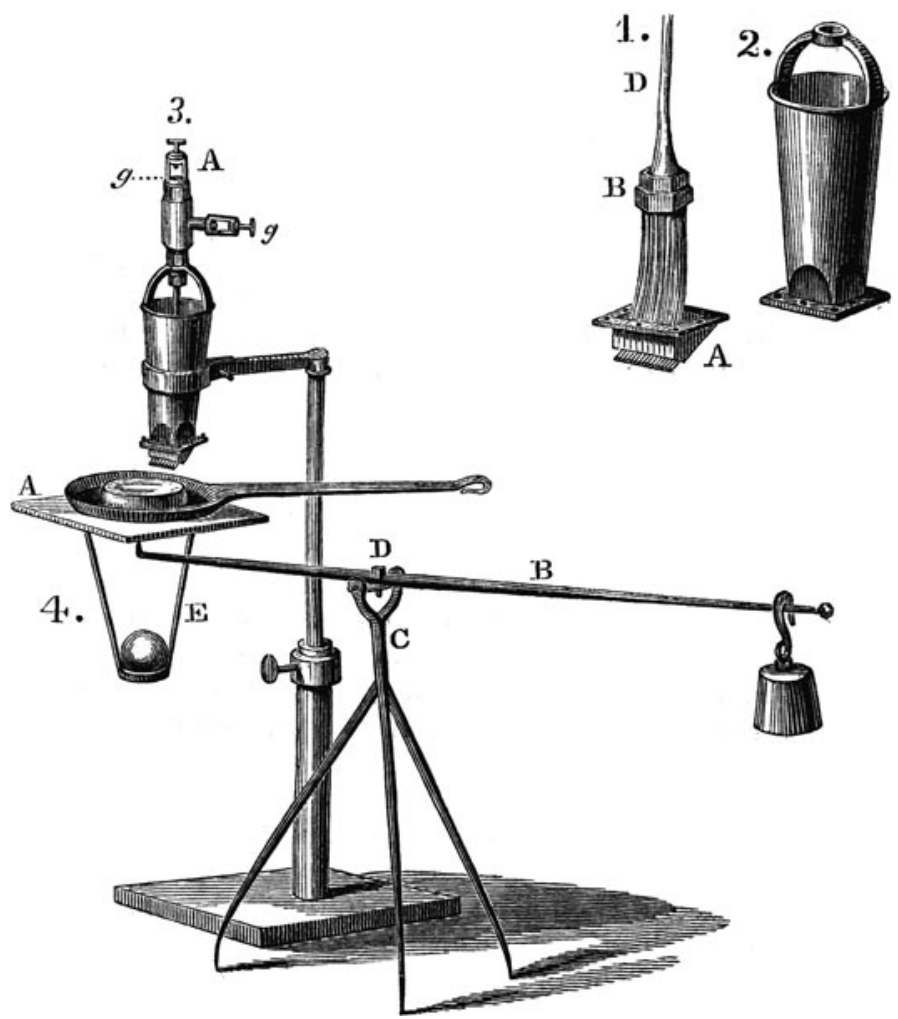

so as to form the bottom thereof, while the pipe, extending above the copper case, is screwed to a hollow cylinder of brass A, fig. 3, provided with two nozzles and gallows-screws $g g$, for the attachment of appropriate hollow knobs, to which pipes are soldered, proceeding from the reservoirs of oxygen and hydrogen. Cocks are interposed by which to regulate the emission of the gases in due proportion.

In connecting the pipes conveying the gases with the brass 
cylinder A, fig. 3, care should be taken to attach that conveying oxygen to the upper nozzle, while the other, conveying hydrogen, should be attached to the lower nozzle; since by these means their great difference in density tends to promote admixture, which evidently it must be advantageous to effect.

The object of surrounding the jet-pipes with water by means of the copper box*, is to secure them against being heated to such a degree as to cause the flame to retrocede and burn within them, so as finally to explode within the cylinder A, $g g$, fig. 3. It is preferable to add ice or snow to the water, in order to prevent undue heat.

Fig, 4 represents a moveable platform $A$, of cast iron, wholly supported upon the point of the iron lever DB, which is curved towards the extremity under the platform, so as to point upwards, and to enter a small central conical · cavity made for its reception. The lever is supported by a universal joint upon the fulcrum $\mathrm{C}$, so that by means of a sliding weight at one end, the platform and its appurtenances are counterpoised at the other. The platform is kept in a horizontal position by the cannon-ball, supported in a sort of iron stirrup terminating in a ring, in which the ball is placed. Upon the platform is situated an iron pan with a handle holding the brick, on a cavity in which, as already mentioned, the metal is supported. The apparatus being duly prepared and connected with the supply-pipes, the hydrogen is first allowed to escape and then the oxygen, until the ignition has attained apparently a maximum. The accomplishment of this object may of course require the adjustment of either cock several times, especially where there is any decline in the pressure either of the one or the other gas in its appropriate reservoir.

By means of the handles of the lever and of the pan, the operator is enabled to bring the metal into the position most favourable for the influence of the heat, while his hands and face are sufficiently remote to render the process supportable. In fusing any quantity, not being more than four ounces, the platform may be dispensed with, the handle of the pan being lield in one hand of the operator, while by the other the cocks may be adjusted.

When the blowpipe of fifteen jets, or any larger, may be

* Since the engraving was made, I have preferred to use water-tight boxes, with gallows-screws and nozzles, situated one near the bottom on one side, the other on the opposite side near the top. By means of the lower nozzle, a pipe is attached, communicating with a head of cold water, the other being so situated as to carry the water into a waste pipe or large tub: a circulation may be kept up during the whole time that the operation is going on,

As a support, a brick knolin is used, having an oblong ellipsoidal depression on the upper face for the reception of the metal to be fused. 
employed, and the platform is necessarily resorted to, the cocks must be adjusted by an assistant.

Fig. 5 represents a cask made of boiler iron, three-sixteenths of an inch thick, so as to resist an enormous pressure. The joints are secured by riveting, as in constructing high pressure boilers.

This cask communicates with the hydrant pipes, so called, by which our city is supplied with water, of which the pressure varies from a half to more than two atmospheres, say from seven to thirty pounds per square inch, according to the number and bore of the cocks from which the water may be flowing at the time for the consumption of the community. Hence experiments, while using this head, are best

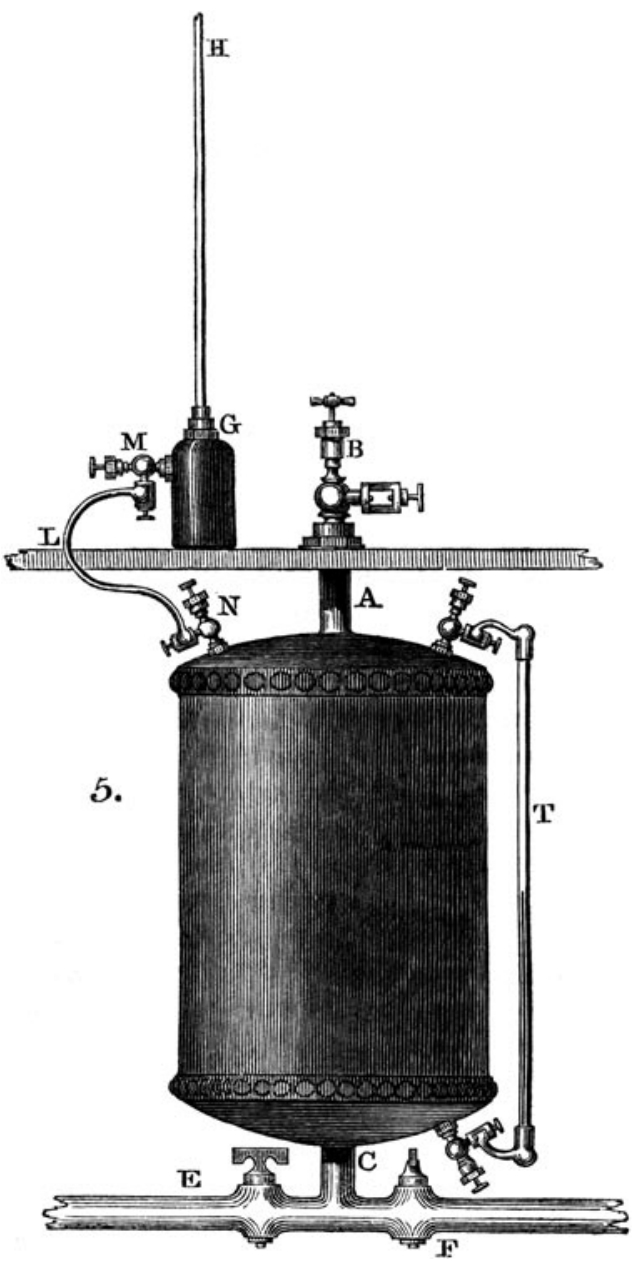
made towards bed-time, or between that time and sunrise. The vessel is filled with water by opening a cock $F$ on one side of the pipe $C$, and allowing the air to escape through the valvecock B. Being thus supplied, the cock F closed, and a communication with a bell-glass, into which oxygen is proceeding from a generating apparatus, being made by means of a flexible leaden tube, on opening the valve-cock $B$ and the cock $E$, the water will run out and be replaced by gas from the bell. This process being continued till the iron cask is sufficiently supplied 
Hydro-Oxygen Blowpipe for the Fusion of Platinum. 361

with gas, the cock $E$ must be shnt. Whenever the gas is wanted for the supply of the blowpipe, it is only necessary to establish a communication between the valve-cock $B$ and the upper gallows-screw (fig. 3) of the cylinder A, and to open the cock $F$, so as to admit the water to press upon the gas, the efflux being regulated by $B$, or preferable by a cock of the ordinary construction, one of which kind should be interposed at a convenient position between the valve-cock $B$ and cylinder A.

T represents a glass tube, which, by due communication with the interior, shows the height of the water, and consequently the quantity of gas in the vessel.

$\mathrm{G} \mathrm{H}$ represents a gauging apparatus, consisting of a castiron flask, of about a half pint in content, and a glass tube of about a quarter of an inch in bore, which should be at least five feet in height. The tube is secured air-tight into the neck of the flask, so as to reach nearly to the bottom within. The flask is nearly full of mercury. Under these circumstances, when a communication is made by a leaden pipe between the cavity of the flask and that of the reservoir, an equilibrium of pressure resulting, the extent of the pressure is indicated by the rise of the mercury in the lube.

In order to generate hydrogen for the supply of a reservoir like that represented by the preceding figure, I have employed the vessel represented by fig. 7 . This vessel, by means of a suitable aperture, susceptible of being closed by a screw-plug, is half-filled with diluted sulphuric acid. Being furnished with a tray of sheet copper $\mathrm{D}$, punctured like a coal-sieve, and supported by a copper sliding $\operatorname{rod} E$, strips of zinc

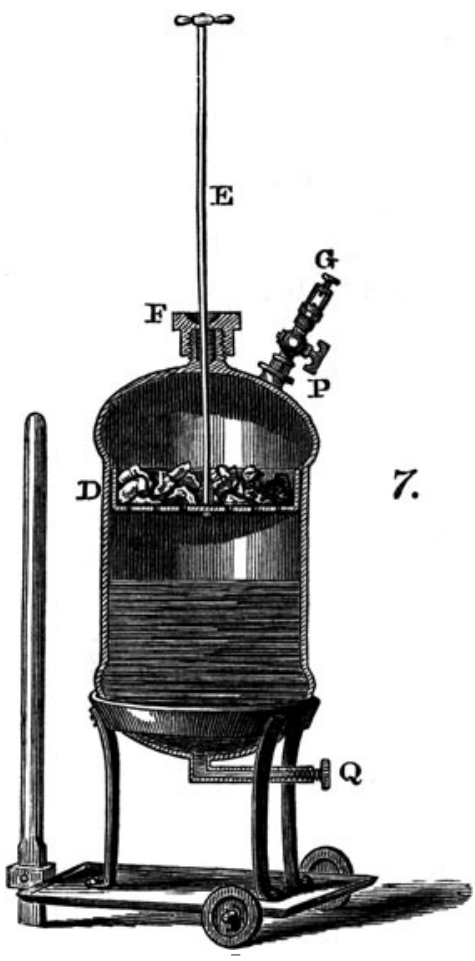
are introduced in quantity equal to the capacity of the tray. The sliding-rod passes through a stuffing-box $\mathrm{F}$, at the top of the reservoir, so that the operator may, by lowering or raising 
the tray, regulate or suspend the reaction between the zinc and its solvent, accordingly as the supply of hydrogen is to be produced, suspended, increased, or diminished.

The communication with the reservoir is open and regulated by means of a cock $P$, furnished with a gallows-screw $G$, for the attachment of a leaden pipe, as above described, in the process for supplying the reservoir with oxygen.

Another apparatus for producing a supply of hydrogen is represented in fig. 6. It consists of two similar vessels of

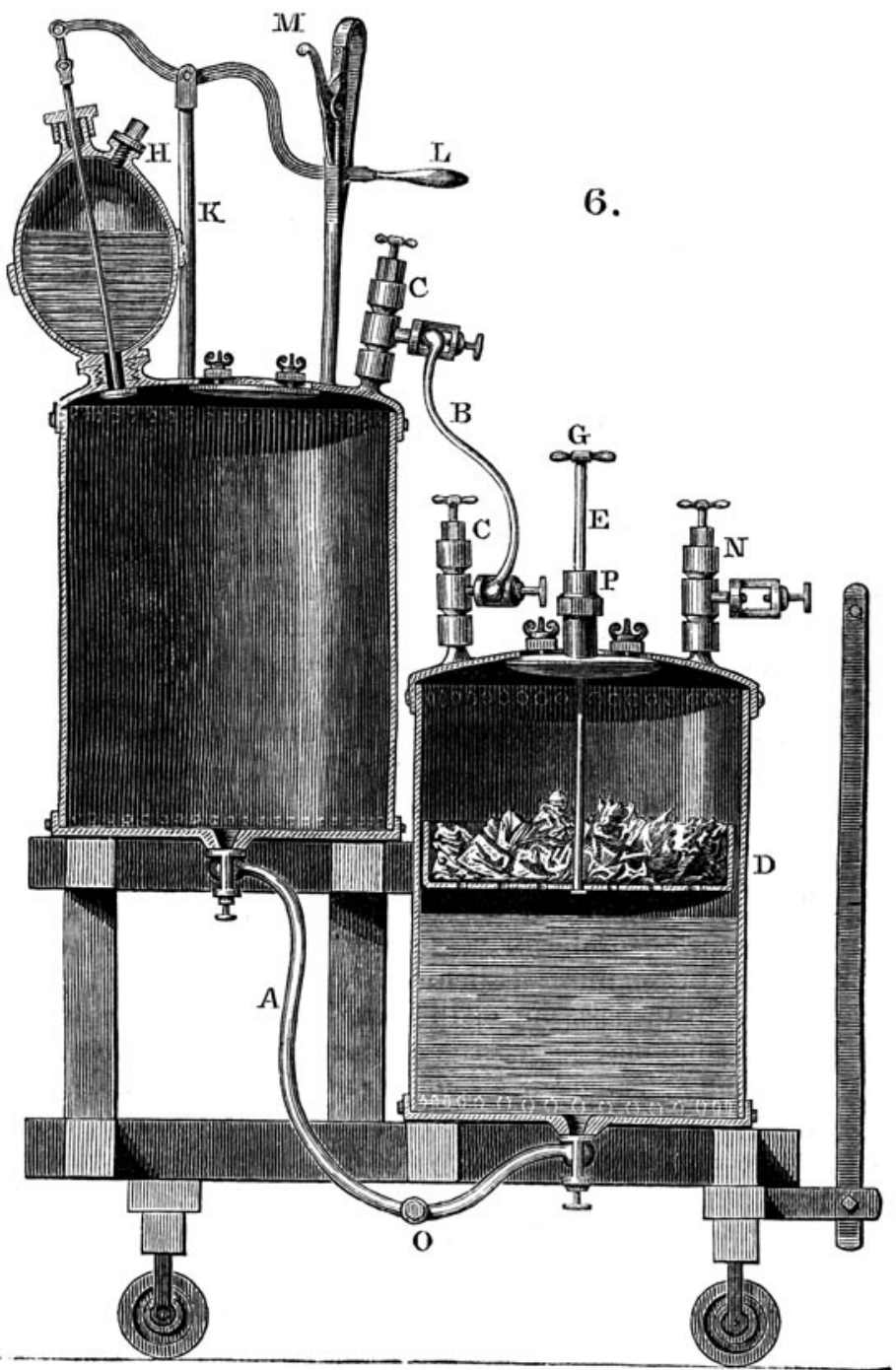


boiler iron, each capable of holding forty gallons. They are lined internally with copper, being situated upon a wooden frame, so that the bottom of one is two-thirds as high as the top of the other. The upper portions of these vessels communicate by a leaden pipe $B$, of about half an inch bore, furnished with a cock, while the lower portions communicate by another leaden pipe of a bore of one and a half inch.

The upper vessel is surmounted by a globular copper vessel, of about twelve inches in diameter, which, from its construction, renders it possible to introduce an additional supply of concentrated acid, while the apparatus is in operation, without reducing the pressure within the reservoir, by permitting the excess above the pressure of the atmosphere to escape. This object is accomplished as follows:-

The valve at the end of the rod attached to the lever $L$ being kept shut by the catch $M$, the screw-plug $H$ removed, the acid is introduced through the aperture thus opened. In the next place, the plug being replaced, and the valve depressed by means of the lever and rod, so as no longer to close the opening which it had occupied, the acid descends from the chamber into the cavity of the vessel beneath it. The valve is of course restored to its previous position as soon as the acid has effected its descent.

The lowermost vessel is furnished with a perforated copper tray, supported by a copper sliding rod, in a way quite analogous to that already described in the case of the copper reservoir. It is also supplied with zinc and its solvent in like manner, being made half-full of the diluted sulphuric acid. Of course, on contact being produced between the zinc and its solvent, the generation of hydrogen will take plare. So long as the communication between the upper portions of the two vessels is open, the gas will extend itself into both, occupying the whole of the upper vessel, and that half of the lower one which is unoccupied by the liquid. But if in this way the pressure reaches to two atmospheres, as indicated by the gauge*, on shutting the communication through the pipe $B$, the pressure in the inferior vessel will augment, that in the superior vessel remaining as before; but the liquid will consequently begin to pass out of the inferior vessel through the pipe $A$, and thus may lessen the contact between the acid and zinc, and finally suspend it altogether. Meanwhile the gas in the upper vessel being condensed to nearly half its previous bulk, the pressure will be nearly four atmospheres. It will,

* I have used for a gauge an instrument like $G$, fig. 5 , the tube being about two feet in length, and sealed at the upper end. 
in fact, always be nearly double that which existed before the pipe $B$ was closed.

In order that nearly the whole of the acid shall be expelled from the inferior vessel, the tray must be depressed till it touches the bottom of that vessel.

The pressure being four atmospheres at commencement, as soon as, by means of a pipe attached to the valve-cock $\mathrm{N}$, an escape of gas is allowed, the acid is forced again upon the zinc, and thus prevents a decline of pressure to any extent sufficient to interfere with the process.

The gases may be used from a receiver in which they exist, in due proportion, safely by the following means :-

Two safety-tubes are to be made, not by Hemming's process exactly, but as follows:

A copper tube, silver soldered, of which the metal is about the eighth of an inch in thickness, is stuffed with the finest copper wire, great care being taken to have the filaments straight and parallel. The tube is then to be subjected to the wire-drawing apparatus, so as to compress the tube on its contents until the draught becomes so hard, as that it cannot be pushed further without annealing. The stuffed tube thus made is to be cut into segments, in lengths about equal to the diameter, by a fine saw. The surfaces of the sections are to be filed gently with a smooth file. By these means they appear to the naked eye like the superficies of a solid metallic cylinder. Brass caps being fitted on these sections, they are to be interposed by soldering, at the distance of a foot or more, into the pipe for supplying the jet. Under these circumstances, the posterior section becoming hot, may allow the flame to retrocede; but the anterior section being beyond the reach of any possible combustion and remaining cold, will not allow of the retrocession; and as soon as the flame passes the first section, the operator, being warned, will of course close the cock, and subject the posterior section to refrigeration before proceeding again.

But this plan of operating may be rendered still more secure by interposing a mercury bottle, or other suitable iron vessel, half-full of oil of turpentine, between the reservoir and safety tubes, as in the arrangement of a Woulfe's bottle. A leaden pipe proceeding from the reservoir is, by a gallowsscrew, attached to an iron tube which descends into the bottle, so that its orifice may be near the bottom. The leaden pipe communicating through the safety tubes with the jetpipe, is attached to the neck of the bottle. Thus the gaseous mixture has to bubble through the oil of turpentine in order to proceed through the safety tubes to the jet-pipe. If, while 
this process is going on, the flame should, by retrocession, reach the cavity of the bottle, exploding in contact with the turpentine, a compound is formed, which is, per se, inexplosive from the excess of carbonaceous matter. Meanwbile the shock, acting on the surface of the oil, drives it into the bore of the iron tube, and thus, both by its chemical and mechanical influence, renders it utterly impossible that the flame should reach the cavity of the reservoir.

\section{Apparatus for the Fusion of Iridium or Rhodium or masses of Platinum less than five ounces in roeight.}

For the fusion of either iridium or rbodium or masses of platinum not exceeding the weight of half an ounce, an instrument with three jets has been employed, the bore of each jetpipe being such as not to admit a wire larger than the $\frac{1}{32}$ nd of an inch in diameter. 'The flame produced by these means was quite sufficient to envelope the mass to which it was applied.

In fusing any lumps or congeries of platinum, not exceeding five ounces, an instrument has been used capable of giving seven jets of gas, issuing of course from as many pipes. Of these pipes, six protrude through the brass casting forming the bottom of the copper case constituting the refrigerator, so as to be equidistant from each other upon a circumference of three-fourths of an inch in diameter, the seventh protruding from the centre. The bores of these jets are such as not to admit a wire larger than $\frac{1}{3 \frac{1}{2}}$ nd of an inch in thickness. Those of the larger instruments, represented by the accompanying engravings, were such as to admit wires of $\frac{1}{2} 4$ th of an inch in thickness.

The jet-pipes may be made by the following process:-A thin strip of sheet metal, somewhat wider than the length of the circumference required in the proposed pipe, after being roughly turned about a wire so as to form an imperfect tube, is drawn through several suitable holes in a steel plate, as in the wire-drawer's process. Under this treatment the strip becomes converted into a hollow wire; the edges of the strip being brought into contact reciprocally, so as to leave only an almost inperceptible crevice. Having drawn one strip of platina in this way, another strip sufficientily wide nearly to inclose it is to be drawn over that first drawn, care being taken to have the crevices left at the meeting of the edges on contrary sides. The compound hollow wire or tube thus fabricated, is finally to be drawn upon a steel wire of the diameter of the requisite bore.

The following method of making jet-pipes, though more 
difficult, is preferable, as there is less liability of the water of the refrigerator leaking into the bore.

Select a very sound and malleable cylinder of platina, of about three-eighths of an inch in thickness, perforate it by drilling in a lathe, so that the perforation may be concentric with the axis. A drill between one-sixteenth and one-eighth of an inch in diameter may be employed. In the next place, the cylinder may be elongated by the wire-drawing process until the proper reduction of metallic thickness is effected, the diameter of the bore being prevented from undergoing an undue diminution by the timely introduction of a steel wire.

Of course the metal must be annealed as often as it hardens, by drawing. For this purpose a much higher temperalure is necessary in the case of platinum, than in that of either copper, silver, or gold.

The annealing is best performed by the hydro-oxygen flame. If charcoal be used, the greatest care must be taken to have the fireplace clean.

Agreeably to a trial made last spring, palladium may be used as a solder for platinum; and as it is nearly as difficult to fuse as this metal, it is of course for that purpose preferable to gold, where great heat is to be resisted. No doubt by employing palladium to solder the exterior juncture of the double drawn tubes above mentioned, they might answer as well nearly as when constructed of solid platinum.

This idea has been verified by a successful trial: and, moreover, silver has been successfully employed to solder the portions of the tubes, protected from heating by being within the cavity occupied by water. The portions which protrude beyond the brass box (see fig. 1) may be left unsoldered.

LIX. On the Composition of the Bile of the Sheep. By J. W. Griffith, M.D., F.L.S., Physician to the Finsbury Dispensary*.

THE following analysis was made with the view of comparing the composition of this fluid with that of the biliary secretion in other animals; the conditions under which the analyses of the bile in them were performed have therefore been observed as closely as possible.

The bile in a perfectly fresh state was evaporated to dryness in a water-bath, the residue powdered and exhausted with alcohol of 840 specific gravity, the solution filtered, and the alcohol distilled off at $212^{\circ} \mathrm{F}$; ; the dry residue was next powdered, dissolved in absolute alcohol, the solution filtered

* Communicated by the Author. 